\title{
The relationship between patient safety culture and adverse events: a study in palestinian hospitals
}

\author{
Shahenaz Najjar ${ }^{1 *}$, Nashat Nafouri ${ }^{2}$, Kris Vanhaecht $^{3}$ and Martin Euwema ${ }^{4}$
}

\begin{abstract}
Background: Patient safety has been considered the heart of healthcare quality. This study aims to explore relationships between patient safety culture and adverse event rates at unit levels in Palestinian hospitals, and provide insight on initiatives to improve patient safety.

Methods: A retrospective, exploratory design was used. Patient safety culture was measured by the Hospital Survey of Patient Safety Culture (HSOPSC) developed by Westat. Adverse events were measured using the Global Trigger Tool (GTT), developed by the Institute for Healthcare Improvement. GT data was collected from patient records discharged May - August 2009 and the HSOPSC data collected in 2010. Descriptive statistics were used to summarize departments' results. Spearman's rho coefficient was used to determine relationships between safety culture and adverse events.

Results: The results showed that -as expected- there exists relationships between safety culture and the rate of adverse events at departmental level. Almost all of the relationships tested were in the expected direction. 8 (57\%) of the 15 relationships were statistically significant $(p<0.05, p<0.01)$, indicating that departments with a more positive patient safety culture had lower rates of adverse events in their department.

Conclusions: Our study confirms the idea that a more positive patient safety culture is associated with lower adverse events in hospitals at the departmental levels in Palestine. Further analysis should include a more representative sample to examine the causal relationship between patient safety culture and adverse events incidents.
\end{abstract}

Keywords: Adverse events, Patient safety culture, Patient safety, Quality, Palestine

\section{Background}

Patient safety has been considered the heart of healthcare quality. Ongoing accidents of tragic harm to patients and the growing complexity of healthcare systems show the need to make healthcare safer, for the same of patients, as well as the health providers and society $[1,2]$.

In the United States, hospital care associated with adverse events and temporary harm events cost Medicare an estimated \$324 million in October 2008. Costs associated with preventable events accounted for an estimated \$119 million of the $\$ 324$ million cost, equating to $1.3 \%$ of the $\$ 9.2$ billion Medicare inpatient expenditures for the month or about $\$ 1.8$ billion annually [3]. Hoonhout et al.

\footnotetext{
* Correspondence: shnaijar@gmail.com

'School of Public Health, Al-Quds University, Jerusalem, Israel, Palestine

Full list of author information is available at the end of the article
}

reported that the annual direct costs were estimated at a total of 355 million Euros for all adverse events and 161 million Euros for preventable adverse events in the Netherlands [4]. Moreover, Vincen et al. reported that, in Britain, the cost of preventable adverse events is 1 billion pounds per annum in lost bed days alone [5]. In response to these costs and quality implications, understanding factors associated with higher/lower rate of adverse events is critical to gain more insight in patient safety and related problems. A widely used definition for patient harm or adverse events is provided by the Institute for Healthcare Improvement (IHI) :"an unintended physical injury resulting from or contributed to by medical care that requires additional monitoring, treatment or hospitalization, or that results in death" [6]. 
Among initiatives to advance patient safety, growing interest has been given to patient safety culture. Safety of the environment affects not only staff, but also patients who might be injured by the actions of staff. The following definition on safety culture is commonly accepted and used. It originated from the nuclear power industry, and was provided by the Advisory Committee on the Safety of Nuclear Installations [7]:

"The safety culture of an organization is the product of individual and group values, attitudes, perceptions, competencies and patterns of behavior that determine the commitment to, and the style and proficiency of, an organization's health and safety programmes. Organization with a positive safety culture are characterized by communications founded on mutual trust, by shared perceptions of the importance of safety, and by confidence in the efficacy of preventative measures"

The Agency for Healthcare Research and Quality (AHRQ) describes culture as a critical component of healthcare quality and safety [8]. Sammer et al. described patient safety culture as the attitudes and behaviors that are related to patient safety and that are expected and appropriate to promote patient safety $[8,9]$.

Considering safety culture as an important initiative to improve patient safety is commonly accepted in healthcare. Although international literature reveals that assessment of patient safety culture and adverse events rate has been in use for decades, hardly any studies have been conducted -and none in the Arab world- that (co) relates these two assessments together [10-12]. Most of the published research on the effect of safety culture, is exploring the relationship between safety outcomes and climate $[13,14]$. The term 'safety climate' is sometimes used interchangeably with 'safety culture', but for others it has a specific meaning. In this view, safety culture is a broad term representing an organization's values and actions related to safety, whereas safety climate focuses on staff perceptions about the way in which safety is managed in their organization. In this study, we were interested in exploring organization's values and actions related to safety. Therefore culture is the main concept of our study. There is some evidence for the relation between patient safety culture and staff outcomes (turnover, burnout) $[15,16]$. Recently, Sorra et al. explored in their study the relationships between safety culture and patient assessments of hospital care [17]. They found that hospitals where staff have more positive perceptions of patient safety culture, their patients have given some positive feedback on the care.

Our study is the first study to our knowledge linking adverse events measured by IHI Global Trigger Tool
(IHI-GTT) and actual adverse events. The overall hypothesis of the study is that a more positive patient safety culture is related to lower rate of hospital adverse events. The aim of this study is to examine whether aspects of safety culture are associated with adverse events rates in two Palestinian hospitals. We study this at the level of hospital departments.

\section{Methods}

\section{Study measures}

The study used the IHI Global Trigger Tool for measuring adverse events and the Hospital Survey on Patient Safety Culture (HSOPSC). The IHI-GTT was originally developed by the Institute for Healthcare Improvement. It is commonly used to measure rates of harm resulting from medical care and provides a reliable measure for them over time $[13,18,19]$. The reviewer conducted a review of each record using the trigger tool consisting of 52 triggers or clues in patient records that indicate the possibility of medically induced harm. When primary reviewers found a trigger (e.g., administration of naloxone, which is often used to reverse the effects of an inadvertent narcotic overdose), they investigated the chart further to determine whether harm resulting from medical care occurred [18]. The tool comprises of six modules: two general triggers with regard to care and medication, and four department specific triggers (surgery, intensive care, perinatal, emergency). The triggers on care and medication should be reviewed in all patient records, but the specific triggers will only be used if applicable [19]. The data courses section below explains these in more details.

HSOPSC was developed by the Westat. It was designed to assess hospital staff perceptions about safety issues. In this assessment, we used the Arabic version of the Hospital Survey of Patient Safety Culture (HSOPSC). It consists of 42 items and is designed to measure ten safety culture dimensions and four outcome measures. The HSOPSC was translated, validated, and then used in our study [20]. The data courses section below explains these in more details.

\section{Participating hospitals}

This study is based on data collected from eight departments within two non-governmental hospitals in the West Bank. These hospitals submitted data to both HSOPSC (2010) and IHI-GTT (patients discharged 2009). The original dataset of safety culture was collected from 13 Palestinian hospitals for a psychometric evaluation study of HSOPSC Arabic version [20]. The adverse events dataset was collected from two general non-governmental hospitals.

The adverse events data was collected from the biggest four departments at both hospitals; namely surgical, obstetrics, internal medicine and orthopaedics which were 
comparable in size at both hospitals. There has been little data concerning AEs in these departments in palestine. We used the trigger on care and medication for all departments and the specific triggers for surgery and obstetrics.

To correlate adverse events data with safety culture data, hospitals submitted both datasets; namely IHIGTT and HSOPSC. Two general non-governmental hospitals met this requirement. The two hospitals serve large communities and are comparable in size and type of departments. They are part of the Palestinian Health System. One of them is a referral teaching hospital and the other is a non-profit, non-governmental hospital. Hospital size ranged from 200 to 250 beds in 2009 [21].

\section{Data courses}

\section{AHRQ Hospital survey on patient safety culture}

For assessment of patient safety culture, the Arabic version of the Hospital Survey of Patient Safety Culture (HSOPSC) was used for this assessment. HSOPSC is one of the few tools which is validated and has a comprehensive report of scale development. It can be applied at hospital-level, and at unit-level $[22,23]$. The HSOPSC was translated, validated, and then used in our study [20]. It consists of 42 items that measure 12 patient safety culture composites. Items are scored on a five-point Likert scale of agreement ( $1=$ 'strongly disagree' to $5=$ 'strongly agree') or scale of frequency $(1=$ 'never' to $5=$ 'always'). Moreover, respondents are asked to provide limited demographic information about themselves (their work area/unit, staff position, whether they have direct interaction with patients, etc.) [24]. We followed the HSOPSC User's Guide [24] for data analysis. First, the percentage of positive scores for each item was calculated. This is the number of positive responses to that item within a department divided by the total number of responses to that item. Positive responses in positively worded survey items were agree/strongly agree' or 'most of the time/always'. Positive responses in negatively worded items were 'disagree/strongly disagree' or 'never/ rarely'. Moreover, composite-level scores were computed by summation of the items within the composite scales and dividing by the number of items. Adding to these composites scores, the survey has also two singleitem outcome measures that ask staff to give their work area/unit a "number of events reported in the past 12 months" and "an overall patient safety grade". Regarding events reported item, more staff reporting events is viewed as a signal of a more positive safety culture rather than negative. "Patient safety grade" is coded as the percentage of participants who gave their work area/unit a grade of excellent (A) or very good (B). The results of these two items are between $0 \%$ and $100 \%$ positive. The model used an aggregate patient safety score that are the summation of patient safety composite scores. Finally, a psychometric evaluation of the Arabic translation of HSOPSC showed that the tool is a valid and reliable instrument to assess patient safety culture in the Arabic speaking hospitals [20]. The Cronbach's coefficient Alpha $(\alpha)$ yielded acceptable reliabilities, ranging between 0.60 and 0.87 [20]. Data used for this particular study was obtained from eight departments $(\mathrm{N}$ contacted $=428, \mathrm{~N}$ responder $=316$ healthcare participants). Aggregate Patient Safety Score (summation of patient safety composite scores).

\section{IHI global trigger tool}

The performance of the original IHI-GTT is established worldwide. Classen et al. found that the adverse event detection methods commonly used to track patient safety in the United States today (voluntary reporting and the AHRQ Patient Safety Indicators) fared very poorly compared to other methods and missed $90 \%$ of the adverse events [25]. The IHI-GTT confirmed ten times more serious events than these other methods [25]. The IHI-GTT version for the present study was assessed and adapted by a group of physicians and researchers within the selected Palestinian hospitals. Specific triggers were added and modified [21]. "The modification and adjustments to Palestinian context are mentioned in Appendix 1: Table 4 in italic and bold". Medical records were randomly selected from patients discharged between May and through August 2009. The randomly selected records produced 80 medical records from each department, 320 medical records from each hospital (640 in total for the study) for review. We followed IHI-GTT instructions for selecting records and screening [6]. Medical records were obtained from patients who were formally admitted to the hospital, with at least $24 \mathrm{~h}$ length of stay, and aged 18 years or older. Furthermore, their records were administratively complete with including discharge summary. The data collection in each hospital team consisted of three persons: two primary record reviewers (experienced nurses) and a physician. The team was selected based on specific and relevant criteria. When primary reviewers identified a trigger, they examined the record to determine whether harm had occurred. Then the two reviewers and the physician met to reach a consensus on the adverse events findings.

\section{Statistical analysis \\ Descriptive statistics}

In line with the aim of our research question, descriptive statistics of hospital surveys of patient safety culture were calculated. The HSOPSC percent positive scores from the analysed hospitals were compared with data from the 2010 HSOPSC comparative database [20, 26]. Descriptive statistics were used to summarize the patient sample characteristics (patients' age, and length of stay), 
adverse event (AE) rate, and aggregate scores of safety culture within the eight departments.

Bivariate correlation was performed in this study to examine associations between $\mathrm{AE}$ rate and safety culture measures (dimensions and outcomes) and aggregate scores. Given data violated parametric assumptions of normal distribution, we considered non-parametric statistics for data analysis. With the relatively limited sample of eight departments, Spearman's rho coefficient was used to test correlations between safety culture and the rate of adverse events. In this test, the ranking order of one variable is related with the ranking order of another variable. In our case ranking of the scores on the different dimensions of the HSOPSC is related with the ranking of the scores (Adverse events rate) on the GTT. Ranking data was done by finding the lowest score and giving it a rank of 1 , then finding the next highest score and giving it a rank of 2, and so on [27]. Given the eight departments, ranking was between 1 and 8 . After that, analysis was carried out on the ranks. Negative associations between HSOPSC measures and adverse event rates were considered when "higher positive HSOPSC measures were associated with lower adverse event rates". Data entry, cleaning, and analysis were done using IBM SPSS version 22.0 (SPSS Inc., Chicago, IL, USA).

\section{Results}

HSOPSC measures \& IHI-GTT related adverse event rate:

Descriptive statistics

Patient safety culture results

The overall response rate of HSOPSC was $74 \%$. Most of the respondents $(88 \%)$ had direct interaction or contact with patients. Eighty-one percert had a working experience of more than one year. The majority of the respondents were nursing staff (50\%), and physicians (38\%), other health professionals $12 \%$. Sixty-four percent worked more than the regular working hours per week $(40 \mathrm{~h})$, and $28 \%$ worked more than $60 \mathrm{~h}$ per week. As shown on Table 1, HSOPSC scores ranged from $17 \%$ positive response (Non-punitive response to error) to $73 \%$ (Teamwork within units). The HSOPSC scores included in our analysis closely matched the statistics from the 2010 HSOPSC Database for the two non-governmental hospitals (NGH), as well as the HSOPSC Database of (eleven governmental hospitals and two non-governmental hospitals) (GH\&NGH) Palestinian hospitals in the West Bank $[20,26]$.

\section{Adverse events results}

640 randomly selected records of hospitalized patients were used. The patient sample had a mean age of 44.2 years (SD: 19.6; range: 18-95) and a mean length of stay of 4.8 days (SD: 5.6; range: $1-70$ ). A total of 91 patient records from the 640 records $(91 / 640 * 100 \%=14.2 \%)$ were found with an AE. By representing our results based on departments, we found that adverse events rates ranged from $6 \%$ (AA_orthopedics) to 24\% (AM_Surgical). Aggregate safety culture ranged from $38 \%$ (AA_Surgical) to $59 \%$ (AM_Obstetrics). Age means were almost comparable within similar departments (range from $28-56$ year). Patient length of stay (LOS) within departments closely matched similar departments (ranged from 2.38-7.40 days). Table 2 shows the descriptive statistical results of patient

Table 1 Descriptive statistics for HSOPSC in eight departments in the study

\begin{tabular}{llllllll}
\hline HSOPSC measures & N & Mean (\%) & SD & Min (\%) & Max (\%) & $\begin{array}{l}\text { NGH Average \% } \\
\text { Positive }\end{array}$ & $\begin{array}{l}\text { GH\&NGH Average \% } \\
\text { Positive }\end{array}$ \\
\hline Supervisor/Manager expectations \& actions promoting & 8 & 50 & 8.20 & 34 & 59 & 54 & 50 \\
patient safety & & & & & & & \\
Organizational learning & 8 & 72 & 9.66 & 52 & 80 & 70 & 63 \\
Teamwork within units & 8 & 73 & 7.65 & 55 & 80 & 78 & 76 \\
Open communication and feedback received on error & 8 & 52 & 13.30 & 30 & 66 & 52 & 46 \\
Non-punitive response to error & 8 & 17 & 9.45 & 4 & 31 & 18 & 16 \\
Staffing & 8 & 29 & 4.49 & 20 & 35 & 41 & 26 \\
Management support for patient safety & 8 & 47 & 6.49 & 39 & 56 & 55 & 46 \\
Teamwork across hospital units & 8 & 45 & 12.17 & 31 & 69 & 43 & 42 \\
Hospital handoffs \& transitions & 8 & 51 & 14.15 & 23 & 73 & 51 & 48 \\
Overall perceptions of safety & 8 & 54 & 9.73 & 42 & 68 & 55 & 49 \\
Frequency of events reported & 8 & 49 & 11.63 & 35 & 69 & 45 & 39 \\
Number of events reported & 8 & 66 & 7.01 & 55 & 77 & 60 & 57 \\
Patient safety grade (very good/excellent) & 8 & 66 & 11.55 & 47 & 88 & 70 & 54 \\
HSOPSC composite average & 8 & 52 & 7.18 & 38 & 59 & 53 & 48 \\
\hline
\end{tabular}

NGH Non-governmental hospital, GH Governmental hospital 
Table 2 Descriptive statistics of in-patients characteristics (age, LOS), patient safety culture, and adverse events rate within eight departments

\begin{tabular}{lllll}
\hline Department & Adverse events rate (\%) & Aggregate patient safety culture (\%) & Patient age Mean (SD) & Length of stay Mean (SD) \\
\hline AA_Surgical & 22 & 38 & $51.89(15.85)$ & $5.29(5.76)$ \\
AM_Surgical & 24 & 44 & $45.09(18.93)$ & $3.31(2.37)$ \\
AA_Internal medicine & 14 & 54 & $56.70(16.06)$ & $7.40(8.29)$ \\
AM_Internal medicine & 13 & 55 & $56.76(19.25)$ & $4.66(3.75)$ \\
AA_Obstatric & 17 & 49 & $29.38(7.78)$ & $3.12(1.50)$ \\
AM_Obstatric & 10 & 59 & $28.31(6.82)$ & $2.38(0.64)$ \\
AA_Orthopedics & 6 & 58 & $49.43(19.16)$ & $6.81(5.68)$ \\
AM_Orthopedics & 7 & 56 & $37.01(21.11)$ & $5.95(8.67)$ \\
\hline
\end{tabular}

safety culture and the rate of adverse events in eight departments.

\section{Correlations}

Examining the correlations revealed significant relationships between HSOPSC measures and adverse events rates (Table 3 ).

Overall higher HSOPSC aggregate scores were associated with lower adverse event rates $(r=-.905, P<0.01)$. Higher positive scores of "supervisor/manager expectation and actions promoting patient safety" were associated with lower adverse event ratings $(r=-.86, p<0.01)$. "Teamwork within units" $(r=-886, \quad P<0.01)$, "open communication and feedback received on errors" $(r=-.905, P<0.01)$, "hospital management support" $(r=-.881, P<0.01)$, "non-punitive response to errors" ( $r=-.731, P<0.05)$, and higher positive scores of "organizational learning" $(r=-.778, P<0.05)$ were also associated negatively and significantly with adverse event rates. Three HSOPSC measures were in the expected direction (negative) but were not statistically significant with the rate of adverse events. These are staffing, teamwork across units, and handoffs and transitions.

By examining the relationships between adverse event rates and HSOPSC self reported outcome measures, higher positive scores on "patient safety grade" (very good/ excellent) were associated with lower adverse event rates $(r=-.738, P<0.05)$. However, "the overall perception of safety, frequency of event reporting, and number of events reported (at least one event during the last 12 months)" were not significantly related with adverse events rates.

\section{Discussion}

The aim of this paper was to explore the correlation between the staff perceptions of patient safety culture and the level of patient safety (adverse event rate) at department level. The overall findings indicated that in departments where staff has more positive patient safety culture perceptions, less adverse events were observed; 8 of 14 HSOPSC measures (12 multi-items dimension and two single item dimentions) were significantly related to the rates of adverse events. The adverse events rates of the departments were comparable within the same department at the two hospitals. However, there was a difference between the obstetric departments (17 \& $10 \%$ ). That difference might be due to 1) AM hospital follows international quality standards in the obstetric department. It has invested in quality improvement efforts and accreditation. 2) AM hospital is a university hospital where some Phycisian and Nurses are highly qualified professors.

The overall correlation between staff ratings of patient safety culture (aggregate safety culture) and ratings of

Table 3 Spearman's rho: correlations between HSOPSC measures and rate of adverse events

\begin{tabular}{lll}
\hline HSOPSC measures & $\begin{array}{l}\text { Correlation Coefficient: } \\
\text { Adverse events rate and }\end{array}$ & Sig. \\
& HSOPSC measures & \\
\hline $\begin{array}{l}\text { Supervisor/manager expectation } \\
\text { and actions promoting patient }\end{array}$ & $-.857^{\mathrm{b}}$ & .003 \\
safety & & \\
Organizational learning & $-.778^{\mathrm{a}}$ & .011 \\
Teamwork within units & $-.886^{\mathrm{b}}$ & .002 \\
Open communication and feedback & $-.905^{\mathrm{b}}$ & .001 \\
received on errors & & \\
Non-punitive response to errors & $-.731^{\mathrm{a}}$ & .020 \\
Staffing & -.060 & .444 \\
Hospital management support & $-.881^{\mathrm{b}}$ & .002 \\
Teamwork across units & -.405 & .160 \\
Handoffs and transitions & -.595 & .060 \\
Overall perception of safety & -.571 & .069 \\
Frequency of event reporting & -.429 & .145 \\
Number of events reported & .429 & .145 \\
Patient safety grade (very good/ & $-.738^{\mathrm{a}}$ & .018 \\
excellent) & & .001 \\
Aggregate safety culture & $-.905^{\mathrm{b}}$ & \\
\hline
\end{tabular}

${ }^{a}$ Correlation is significant at the 0.05 level (1-tailed) ${ }^{\mathrm{b} C}$ Correlation is significant at the 0.01 level (1-tailed) 
adverse events in our study shown in Table 3 was highly significant $(r=-.905(P<0.01))$. It is important to note that our results indicated that staff perceptions of patient safety culture are related to patient safety rate. Mardon's et al. examined relationships between HSOPSC and rates of hospital complications by using patient safety indicators on a hospital level [28]. Our study is the first study exploring relationships between HSOPSC and IHI-GTT at department level. Other researchers assessed the relationship between hospital climate and patient safety performance indicators, and concluded the same negative correlations; hospitals with better patient safety climate had fewer patient safety incidents [13].

A few previous criterion studies have related positive patient safety culture to safety outcomes such as slightly decreased mortality rates and length of stay [29]. Other criterion studies examining the relationships between HSOPSC and patient experiences with hospital care and services by using the Consumer Assessment of Healthcare Providers and Systems Hospital Survey (Hospital CAHPS) found that higher overall HSOPSC composite average scores were associated with higher overall Hospital CAHPS [17]. There is some evidence that safety culture impacts on staff outcomes, but less evidence of an impact on patient outcomes [30-39]. This study explored the correlation between safety culture on patient outcomes.

A further interesting finding was the different relations we found between the dimensions of patient safety culture in our study. The data suggested that more 'soft' factors, such as interaction, "communication and teamwork", were stronger related with adverse events rates, while more 'hard' factors such as" staffing, frequency and number of reporting", were less related to adverse events. The strongest relationships $(P<0.01)$ among the various composites were between the HSOPSC measure of the "open communication and feedback received on errors" $r=-0.905$, "teamwork within units" $r=-0.886$, "hospital management support" $r=-0.881$, and "supervisor/manager expectation and actions promoting patient safety" $r=-0.857$, followed by, another two patient safety culture areas "organizational learning" $r=-0.778$ and "non-punitive response to errors" $r=-0.731$, which showed strong relationships $(P<0.05)$ to adverse event rate as well. "Staffing" was the weakest correltion $(r=-0.06, P<\mathrm{O} .44)$ with adverse events. There is a need for more evidence linking the HSOPSC and rate of adverse event. A more detailed measurement is needed to validate which intervention has an impact on adverse events rate. To our knowledge the participating hospitals invested in interventions that maintained organizational learning, continuous improvement and sustained teamwork within units. The correlation results should encourage other hospitals and departments to invest in such interventions. One of the most useful tools to improve teamwork is TeamSTEPPS [40]. The benefit of this tool is not only the improvement of teamwork within and across units, it strengthens the communication and feedback skills about errors and builds a learning system from mistakes as well.

The "overall perceptions of patient safety culture, patient safety grade, frequency of event reporting, no events reported", and adverse event rate were not significant in their association with adverse event rates, however the relations were all in the expected direction, and a larger sample might show significant relations for these dimensions. It is worthy to mention that patient safety grade (very good/excellent) was associated significantly with lower adverse event rates. Brewer's study had a similar finding in that negative association [41]. In general, the two used tools which are valid and well-structured instruments. They were appropriate to discover correlations between specific safety culture dimensions and adverse events rate. However, future studies are needed to investigate the real impact of some specific interventions to improve safety culture on adverse events rate.

\section{Study limitations and future research}

This pilot study was a foundation step in exploring the relationship/correlation between patient safety culture and adverse event rates in Palestine. It is the first study that links results of HSOPSC with IHI-GTT on department level, showing mostly a strong relation between staff reports on patient safety culture, and independent assessment of adverse events. The current study has some methodological limitations that should be addressed. First, due to resource constraints we were able to conduct the analysis on a small group of 8 departments in two NGO hospitals that voluntarily agreed to participate in the study. Size of sample limits generalizing our findings. However, it is worthy to mention that data collected from HSOPSC and IHI-GTT was collected by participating departments around the same period between 2009 \& 2010 . Moreover, the overall response rate was $74 \%$ from which $50 \%$ nursing staff and $38 \%$ physicians. As our study did not analyse the impact of safety culture on adverse events, but solely examined the correlation (exploratory study), more studies are needed to better understand the relationships that exist and the impact of changes in patient safety culture on patient outcomes. Future studies might be done on hospital levels by controlling hospital characteristics (e.g. using multiple regression) to have an accurate assessment of the relationship between those measures. Moreover, future studies might be on department level by controlling departmental confounders (e.g. patient staff ratio or case mix).

A second limitation is that our HSOPSC study used a cross-sectional design that discerns the causality of the relationship between patient safety culture and adverse event rates. A controlled study design (cluster 
RCT) is needed to examine the effectiveness of safety culture improvement initiatives, and further evaluate causality relationships. Also, this pilot study justifies the exploration of the overall adverse event rate that occurred frequently in hospitals. Specific safety outcomes that seem to have the greatest impact, such as mortality, should be included in future studies to provide evidence on relationships that might exist.

\section{Conclusions}

The present analysis revealed correlatios between HSOPSC and IHI-GTT for measuring adverse events that provide initial evidence that these measures would be negatively related. Significant statistical correlations

were found between HSOPSC measures and adverse events rates by IHI-GTT. Future analyses should include a more representative sample of departments/ hospitals to be able to have enough power to detect more associations between these measures. Overall this study is an important first step in assessing the associations between these two well-known measures of patient safety culture and adverse events in hospitals. The overall results show that departments that have a higher positive response on patient safety cultures have less adverse events.

\section{Appendix 1}

Table 4 Palestinian version of the Institute for Healthcare Improvement Global Trigger Tool (IHI-GTT) for measuring adverse events

\begin{tabular}{|c|c|c|c|c|c|}
\hline \multicolumn{2}{|c|}{ Care module triggers } & \multirow{2}{*}{$\begin{array}{l}\text { Event description and } \\
\text { harm category (E-I) }\end{array}$} & \multicolumn{2}{|c|}{ Medication module triggers } & \multirow{2}{*}{$\begin{array}{l}+ \text { Event description and } \\
\text { harm category (E-I) } \\
\end{array}$} \\
\hline $\mathrm{C} 1$ & $\begin{array}{l}\text { Transfusion or use of blood } \\
\text { products }\end{array}$ & & M1 & Clostridium difficile positive stool & \\
\hline $\mathrm{C} 2$ & Code/arrest/rapid response team & & M2 & Partial thromboplastin time greater than $100 \mathrm{~s}$ & \\
\hline C3 & Acute dialysis & & M3 & $\begin{array}{l}\text { International Normalized Ratio (INR) greater } \\
\text { than } 6\end{array}$ & \\
\hline C4 & Positive blood culture & & M4 & Glucose less than $50 \mathrm{mg} / \mathrm{dl}$ & \\
\hline C5 & $\begin{array}{l}\text { X-ray or Doppler studies for emboli } \\
\text { or deep vein thrombosis (DVT) }\end{array}$ & & M5 & $\begin{array}{l}\text { Rising blood urea nitrogen (BUN) or serum } \\
\text { creatinine greater than } 2 \text { times baseline }\end{array}$ & \\
\hline C6 & $\begin{array}{l}\text { Decrease of greater than } 25 \% \text { in } \\
\text { hemoglobin or hematocrit }\end{array}$ & & M6 & Vitamin $\mathrm{K}$ administration & \\
\hline C7 & Patient fall & & M7 & Benadryl (Diphenhydramine) use & \\
\hline $\mathrm{C} 8$ & Pressure ulcers & & M8 & Romazicon (Flumazenil), Anexate, Mazicon use & \\
\hline C9 & Readmission within 30 days & & M9 & Naloxone (Narcan) Nalone, Narcanti use & \\
\hline $\mathrm{C} 10$ & Restraint use & & M10 & Antiemetic use & \\
\hline C11 & Health care-associated infection & & M11 & Over-sedation/hypotension & \\
\hline $\mathrm{C} 12$ & In-hospital stroke & & M12 & Abrupt stop of medication & \\
\hline $\mathrm{C} 13$ & Transfer to higher level of care & & M13 & Skin rash & \\
\hline C14 & Any procedure complication & & M14 & Other & \\
\hline \multicolumn{6}{|c|}{ C15 Other } \\
\hline \multicolumn{3}{|c|}{ Surgical Module Triggers } & \multicolumn{3}{|c|}{ Intensive Care Module Triggers } \\
\hline S1 & Return to surgery & & 11 & Pneumonia onset & \\
\hline S2 & $\begin{array}{l}\text { Change in anesthetic or procedure } \\
\text { during surgery }\end{array}$ & & 12 & Readmission to intensive care & \\
\hline S3 & Admission to intensive care post-op & & 13 & In-unit procedure & \\
\hline S4 & $\begin{array}{l}\text { Intubation/reintubation/BiPap in } \\
\text { Postanesthesia Care Unit (PACU) }\end{array}$ & & 14 & Intubation/reintubation & \\
\hline S5 & $X$-ray intra-op or in PACU & & & & \\
\hline S6 & Intra-op or post-op death & & \multicolumn{3}{|c|}{ Prenatal module triggers } \\
\hline S7 & $\begin{array}{l}\text { Mechanical ventilation greater } \\
\text { than } 24 \mathrm{~h} \text { post-op }\end{array}$ & & P1 & Terbutaline use & \\
\hline S8 & Intra-op epinephrine, norepinephrine, & & P2 & 3rd- or 4th-degree lacerations & \\
\hline
\end{tabular}


Table 4 Palestinian version of the Institute for Healthcare Improvement Global Trigger Tool (IHI-GTT) for measuring adverse events (Continued)

\begin{tabular}{|c|c|}
\hline 59 & $\begin{array}{l}\text { Post-op troponin level greater than } \\
1.5 \mathrm{ng} / \mathrm{ml}\end{array}$ \\
\hline S10 & Injury, repair, or removal of organ \\
\hline S11 & Any operative complication \\
\hline$S 12$ & Consult request post-anesthesia \\
\hline
\end{tabular}

\author{
P3 Platelet count less than 50,000 \\ P4 Estimated blood loss $>500 \mathrm{ml}$ (vaginal) \\ or $>1,000 \mathrm{ml}$ (C-section) \\ P5 Specialty consult \\ P6 Oxytocic agents \\ P7 Instrumented delivery \\ P8 General anesthesia \\ P9 Maternal/neonatal transport/transfer \\ Emergency department (ED) module triggers \\ E1 Readmission to ED within $48 \mathrm{~h}$ \\ E2 Time in ED greater than $6 \mathrm{~h}$
}

\begin{tabular}{l}
\hline Patient Identifier \\
Worksheet. [Opposite side is blank for notes.]
\end{tabular} Total Events ___ Total LOS __ Write descriptions of the events in greater detail on reverse of

\begin{abstract}
Abbreviations
HSOPSC: Hospital Survey of Patient Safety Culture; IHI: Institute for Healthcare Improvement; AHRQ: Agency for Healthcare Research and Quality; IHIGTT: Institute for Healthcare Improvement-Global Trigger Tool; AE: Adverse Event; AA and AM: Codes for Participating Hospitals; LOS: Length of Stay; Hospital CAHPS: Consumer Assessment of Healthcare Providers and Systems Hospital Survey; Cluster RCT: Cluster Randomised Control Trial; NGH: Nongovernmental hospital; GH: Governmental hospital.
\end{abstract}

\section{Competing interests}

The authors declare that they have no competing interests.

\section{Authors' contributions}

The authors all contributed in the writing and review of the manuscript. SN: Statistical analyses of the data, Data collection and draft of the manuscript. NN: Intellectual content, KV: Study design and outline, ME: Analysis and interpretation of data. All authors read and approved the final manuscript.

\section{Acknowledgements}

We particularly acknowledge all the nurses, physicians and quality supervisors who reviewed the medical records and used the GTT during our study at the two hospitals. We extend our gratitude to the participant hospitals and to their staff who devoted time to complete the surveys. Special thanks go to the School of Public Health, Centre for Health Services and Nursing Research; KU Leuven for supporting this research study.

\section{Author details}

${ }^{1}$ School of Public Health, Al-Quds University, Jerusalem, Israel, Palestine. ${ }^{2}$ King Abdul Aziz Medical Center, King Abdullah Economic city, Saudi Arabia. ${ }^{3}$ Department of Quality Management, UZLeuven, School of Public Health, KULeuven (University of Leuven), Leuven, Belgium. ${ }^{4}$ Coordinator research group Work, Organizational and Personnel Psychology, KULeuven (University of Leuven), Leuven, Belgium.

Received: 29 March 2015 Accepted: 3 August 2015

Published online: 09 September 2015

\section{References}

1. The Research Priority Setting Working Group of WHO Patient Safety. Summary of the evidence on patient safety: Implications for research. Geneva: WHO 2008. http://www.who.int/patientsafety/information_centre/ 20080523_Summary_of_the_evidence_on_patient_safety.pdf.

2. Kohn KT, Corrigan JM, Donaldson MS. To err is human: building a safer health system. Washington, DC, USA: National Academy Press; 2000. Ref Type: Report.
3. Levinson D. Department of Health and Human Services. Office of inspector general. USA: Adverse events in hospitals: national incidence among medicare beneficiaries. November 2010, OEl-06-09-00090.

4. Hoonhout LH, de Bruijne MC, Wagner C, Zegers M, Waaijman R, Spreeuwenberg $P$, et al. Direct medical costs of adverse events in Dutch hospitals. BMC Health Serv Res. 2009;9:27.

5. Vincent C. Clinical risk management. Secondth ed. London: BMJ books; 2001.

6. Griffin FA, Resar RK. IHI Global Trigger Tool for Measuring Adverse Events (Second Edition).IHI Innovation Series white paper. Cambridge, MA: Institute for Healthcare Improvement, 2009. Available on http://www.ihi.org/Pages/default.aspx.

7. Health and Safety Commission (of Great Britain). Organizing for safety: Third report of the ASCNI (Advisory Committee on the safety of Nuclear Installations) Study Group on Human Factors, UK, 1993.

8. Agency for Healthcare Research and Quality. (n.d.). Retrieved from http:// www.ahrq.gov/professionals/quality-patient-safety/patientsafetyculture/ hospital/index.html).

9. Sammer C, James B. Patient Safety Culture: The Nursing Unit Leader's Role. Online J Issues Nurs. 2011;16(3):3.

10. Pfeiffer $Y$, Manser T. Development of the German version of the Hospital Survey on Patient Safety Culture: Dimensionality and psychometric properties. Saf Sci. 2010;48:1452-62.

11. Flin R. Measuring safety culture in healthcare: A case for accurate diagnosis. Saf Sci. 2007:45:653-67.

12. Pronovost $P$, Sexton B. Assessing safety culture: guidelines and recommendations. Qual Saf Health Care. 2005;14:231-3.

13. Sara S, Lin S, Alyson F, David G, Laurence B. Relationship of safety climate and safety performance in hospitals. Health Serv Res. 2009;44(2 Pt 1):399-421. doi:10.1111/j.1475-6773.2008.00918.x. Epub 2008 Nov 4.

14. Rosen AK, Singer S, Shibei Z, Shokeen P, Meterko M, Gaba D. Hospital safety climate and safety outcomes: is there a relationship in the VA? Med Care Res Rev. 2010;67(5):590-608. doi:10.1177/1077558709356703. Epub 2010 Feb 5.

15. The health foundation. Research scan: Does improving safety culture affect patient outcomes? The health foundation United kingdom, UK. November 2011.

16. Timmel J, Kent PS, Holzmueller CG, Paine L, Schulick RD, Pronovost PJ. Impact of the Comprehensive Unit-based Safety Program (CUSP) on safety culture in a surgical inpatient unit. Jt Comm J Qual Patient Saf. 2010;36(6):252-60.

17. Sorra J, Khanna K, Dyer N, Mardon R, Famolaro T. Exploring relationships between patient safety culture and patients' assessments of hospital care. J Patient Saf. 2012;8(3):131-9. doi:10.1097/PTS.0b013e318258ca46.

18. Landrigan CP, Parry GJ, Bones CB, Hackbarth AD, Goldmann DA, Sharek PJ, et al. Temporal trends in rates of patient harm resulting from medical care. N Engl J Med. 2010;363:2124-34. 
19. Resar RK, Rozich JD, Classen D. Methodology and rationale for the measurement of harm with trigger tools. BMJ Qual Saf. 2003;12:ii39-45.

20. Najjar S, Hamdan M, Baillien E, Vleugels A, Euwema M, Sermeus W, et al. The Arabic version of the hospital survey on patient safety culture: a psychometric evaluation in a Palestinian sample. BMC Health Serv Res. 2013;13:193. doi:10.1186/1472-6963-13-19.3.

21. Najjar S, Hamdan M, Euwema M, Vleugels A, Sermeus W, Massoud R, et al. The Global Trigger Tool shows that one out of seven patients suffers harm in Palestinian hospitals: challenges for launching a strategic safety plan. Int J Qual Health Care. 2013;25:1-8.

22. Flin R, Burns C, Mearns K, Yule S, Robertson EM. Measuring safety climate in health care. Qual Saf Health Care. 2006;15:109-15.

23. Colla JB, Bracken AC, Kinney LM, Weeks WB. Measuring patient safety climate: a review of surveys. Qual Saf Health Care. 2005;14:364-6.

24. Sorra J, Famolaro T, Dyer N, Nelson D, Smith SA. Hospital Survey on Patient Safety Culture: 2012 User Comparative Database Report. Prepared by Westat, Rockville, MD, under Contract No. HHSA 290200710024C. AHRQ Publication No. 12-0017, January 2012. Agency for Healthcare Research and Quality, Rockville, MD. http://www.ahrq.gov/sites/default/files/wysiwyg/ professionals/quality-patient-safety/patientsafetyculture/hospital/2012/ hospsurv121.pdf.

25. Classen D, Resar R, Griffin F, Federico F, Frankel T, Kimmel N, et al. 'Global Trigger Tool' shows that adverse events in hospitals may be ten times greater than previously measured. Health Aff. 2011;30:581-9.

26. Hamdan M, Saleem A. Assessment of patient safety culture in Palestinian public hospitals. Int J Qual Health Care. 2013;25(2):167-75.

27. Field A. Discovering Statistics using SPSS. 3rd ed. London: Sage; 2009. p. 540.

28. Mardon RE, Khanna K, Sorra J, Dyer N, Famolaro T. Exploring relationships between hospital patient safety culture and adverse events. J Patient Saf. 2010;6:226-32.

29. Huang DT, Clermont G, Sexton JB, Karlo CA, Miller RG, Weissfeld LA, et al. Perceptions of safety culture vary between the ICU's of a single institution. Crit Care Med. 2007;35:165-76.

30. Chen IC, Ng HF, Li HH. A multilevel model of patient safety culture: cross-level relationship between organizational culture and patient safety behavior in Taiwan's hospitals. Int J Health Plann Manage. 2012;27(1):e65-82. doi:10.1002/hpm.1095. Epub 2011 Jun 3.

31. Jiang L, Yu G, Li Y, Li F. Perceived colleagues' safety knowledge/ behavior and safety performance: safety climate as a moderator in a multilevel study. Accid Anal Prev. 2010;42(5):1468-76.

32. Olsen E. Exploring the possibility of a common structural model measuring associations between safety climate factors and safety behaviour in health care and the petroleum sectors. Accid Anal Prev. 2010;42(5):1507-16.

33. Stahl K, Augenstein J, Schulman IC, Wilson K, McKenney M, Livingstone A. Assessing the impact of teaching patient safety principles to medical students during surgical clerkships. J Surg Res. 2011;170:e20-40.

34. Naveh E, Katz-Navon T, Stern Z. Readiness to report medical treatment errors: the effects of safety procedures, safety information, and priority of safety. Med Care. 2006;44(2):117-23.

35. Frey B, Schwappach D. Critical incident monitoring in paediatric and adult critical care: from reporting to improved patient outcomes? Curr Opin Crit Care. 2010;16(6):649-53. doi:10.1097/MCC.0b013e32834044d8.

36. MacDavitt K, Chou SS, Stone PW. Organizational climate and health care outcomes. Jt Comm J Qual Patient Saf. 2007;33 Suppl 1:45-56.

37. Gershon RR, Stone PW, Zeltser M, Faucett J, MacDavitt K, Chou SS. Organizational climate and nurse health outcomes in the United States: a systematic review. Ind Health. 2007:45(5):622-36.

38. Clarke SP, Sloane DM, Aiken LH. Effects of hospital staffing and organizational climate on needlestick injuries to nurses. Am J Public Health 2002;92(7):1115-19.

39. Clarke SP, Rockett JL, Sloane DM, Aiken LH. Organizational climate, staffing, and safety equipment as predictors of needlestick injuries and near-misses in hospital nurses. Am J Infect Control. 2002;30(4):207-16.

40. Hudson DW, Sexton BJ, Thomas EJ, et al. A safety culture Primer for the critical care Clinician: the role of culture in patient safety and quality improvement. Contemp Crit Care. 2009;7:1-14.

41. Brewer BB. Relationships among Teams, Culture, Safety, and Cost Outcomes. West J Nurs Res. 2006:28(6):641-53.

\section{Submit your next manuscript to BioMed Central and take full advantage of:}

- Convenient online submission

- Thorough peer review

- No space constraints or color figure charges

- Immediate publication on acceptance

- Inclusion in PubMed, CAS, Scopus and Google Scholar

- Research which is freely available for redistribution

Submit your manuscript at www.biomedcentral.com/submit 